\title{
The South African Society of Psychiatrists/Psychiatry Management Group management guidelines for adult attention-deficit/hyperactivity disorder
}

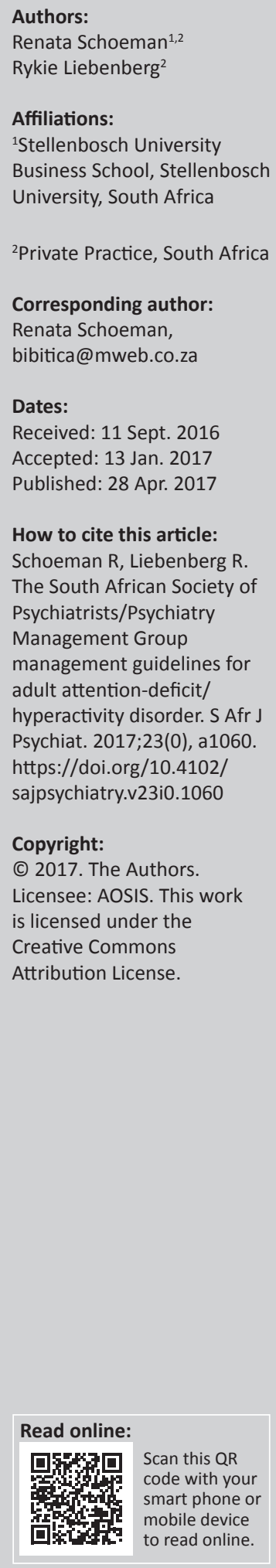

Disclaimer: These guidelines do not aim to provide a comprehensive review of all the pertinent literature comprising the evidence base and, as such, should be utilised in conjunction with other guidelines as well as the responsibility of practitioners to maintain a high level of personal knowledge and expertise. Despite the known efficacy of treatment and the substantial costs of untreated attention-deficit/hyperactivity disorder (ADHD), access to healthcare and treatment is not a given for many patients in South Africa (SA). In SA, there is poor identification and treatment of common mental disorders at primary healthcare level and limited access to specialist resources with a service delivery and treatment gap of up to $75 \%$. Medication options are also often limited in emerging markets and in SA psychiatrists, and patients do not have access to the medication armamentarium available in established markets. Furthermore, the majority of South Africans currently utilise the public healthcare sector and may not have access to treatment options referred to in these guidelines. These guidelines should therefore not be seen as a policy document.

The process: The South African Society of Psychiatrists' Special Interest Group (SIG) for adult ADHD was launched on 25 September 2015, with doctors Rykie Liebenberg and Renata Schoeman as convenor and co-convenor, respectively. The overall objective of the ADHD SIG is to improve the basket of care available to patients with ADHD. This is only possible through a combined and concerted effort of individuals with a special interest in and passion for ADHD to improve knowledge about and funding for the care of individuals with the disorder. One of the specific aims of the ADHD SIG was to develop South African guidelines for the diagnosis and treatment of adult ADHD specifically and update guidelines for the treatment of child, adolescent and adult ADHD. Dr Schoeman has recently completed her MBA at the University of Stellenbosch Business School with a thesis entitled 'A funding model proposal for private health insurance for adult attention-deficit/hyperactivity disorder in the South African context'. This is first South African study exploring the situation with regard to the prevalence and treatment of adult ADHD. Dr Schoeman was tasked by the SIG with the drafting of guidelines. Dr Liebenberg provided valuable input. The guidelines were then circulated to the SIG members, as well as the Chair of the Public Sector SIG, for written feedback and evidencebased suggestions which were then incorporated into the guidelines. The final guidelines were circulated for written approval by the SIG members, followed by formal approval at a SIG meeting held on 14 August 2016, after which it was submitted to the South African Society of Psychiatrists (SASOP) and Psychiatry Management Group (PsychMG) boards for recommendation and ratification.

\section{Introduction}

'Mental restlessness' was first described by Sir Alexander Crichton in 1798, ${ }^{1}$ while 'Fidgety Philip' (a popular storybook character and now also an allegory for children with attention-deficit/ hyperactivity disorder [ADHD]) was created by Heinrich Hoffmann in $1844 .^{2}$ Sir George Still's Goulstonian Lectures, ${ }^{3}$ describing children with restlessness, inattention and impulsiveness, can be considered the starting point of the description 'attention-deficit/hyperactivity disorder' (ADHD) as we know it.

The notion that ADHD is a disorder of childhood prevailed until the 1990s. Rigorous research, including longitudinal studies, and public awareness highlighted the presence of ongoing symptoms in $65 \%$ of adult patients. ${ }^{4,5}$ Adult ADHD is now a recognised problem. Associated symptoms of ADHD include behavioural, cognitive, emotional and social problems. Problems with planning, 
task initiation, task completion, impatience and impulsivity can cause numerous work-related and interpersonal problems.

\section{Prevalence}

ADHD is the most common psychiatric disorder in children affecting $2.0 \%-16.0 \%$ of the school-age population. ${ }^{6}$ The population prevalence for ADHD is estimated as $3.0 \%-$ $5.0 \%{ }^{7}$ It is now widely accepted that an estimated $60.0 \%-$ $70.0 \%$ of patients' symptoms persist into adulthood, ${ }^{8}$ with estimates of the prevalence of adult ADHD between 2.5\% $4.3 \% .{ }^{9,10,11}$ ADHD is more frequent in men than in women in the general population, with a ratio of approximately 1.6:1 in adults. Women are more likely than men to present primarily with inattentive features. The increased diagnosis of ADHD over the past decade seems to reflect improved criteria for the identification of ADHD in adults and female patients. ${ }^{12,13,14,15,16}$

The specific lifetime prevalence of ADHD in South Africa (SA) is unknown. The South African Stress and Health study, a nationally representative household survey of 4351 adults, conducted between 2002 and 2004, investigated the prevalence and treatment access and use for mental health disorders. Unfortunately, results were grouped as anxiety disorders, mood disorders, substance use disorders (SUD), and 'any other disorder'. ADHD would be included within the last group, with a prevalence of $30.3 \% .{ }^{17,18}$

In the first South African study exploring the situation with regard to the prevalence and treatment of adult ADHD, ${ }^{19}$ extrapolating the known prevalence information to the South African context, the expected number of adults between the age of 20 and 50 years affected by ADHD was calculated to be between 771264 (3\%) and 1285439 (5\%). In this triangulated study (consisting of a database analysis of one of the largest medical scheme administrators in SA in terms of medical, pharmaceutical and claims data for the treatment of ADHD over a 2-year period; a survey with psychiatrists in private practice who manage adult ADHD; and a qualitative analysis of in-depth interviews with key opinion leaders on their experiences in working with adults with ADHD), the population prevalence of adult ADHD was estimated at 1.09\%, whereas the prevalence in clinical psychiatric settings was as high as $52.5 \%$, of which $13.68 \%$ were patients with newlydiagnosed ADHD. Conditions comorbid with adult ADHD are common with psychiatric conditions in up to $20.43 \%$ of individuals. In this study, lack of knowledge of adult ADHD and lack of funding for the treatment thereof were identified as the two main barriers to diagnosis and treatment. It is therefore possible that these prevalence rates are underestimating the true prevalence of adult ADHD in SA.

\section{Costs}

ADHD is a costly, chronic disorder, with significant impact on the quality of life of patients and their families. The burden of disease is significant, with the disability-adjusted life years (DALYs) calculated as 424 per $100000 .^{20}$ The economic burden of adult ADHD (\$3020 per patient per annum) is less than those of depression and diabetes, but more so than seasonal allergy. ${ }^{21}$

Significant comorbidity, estimated at more than 50\% with ADHD, contributes to the burden of disease and reduced quality of life of patients with ADHD. Adults with ADHD are more likely to suffer from comorbid medical disorders (e.g. asthma, unplanned pregnancies and sexually transmitted diseases), as well as psychiatric disorders (e.g. mood disorders, anxiety disorder, substance abuse disorders and behavioural disorders). ${ }^{22,23}$

(Untreated) ADHD also impairs educational attainment and employment status, impairs work performance (reduced productivity and increased absenteeism), adversely affects interpersonal relationships (irritability and low frustration tolerance) and adds to significant societal costs (because of substance abuse and accidents). ${ }^{24,25,26,27,28,29,30,31}$

Persons with ADHD have lower self-esteem and general happiness with life, higher divorce rates and problems keeping friends and are at risk of forensic contact. . $6,32,33,34,35^{-1}$

In a South African study, ${ }^{19}$ the presence of adult ADHD more than doubled the healthcare costs of medical scheme beneficiaries. However, the costs attributable to direct costs of ADHD formed only $0.56 \%$ of the total value of claims. Of this, medication was the largest expense $(5.47 \%$ of total costs and $38.48 \%$ of direct costs), whereas psychiatric services formed only $3.27 \%$ of the direct costs. This is in agreement with international finding $\mathrm{s}^{28}$ where the cost of medication for treatment of ADHD amounted to $7 \%$ of all direct and indirect costs. This would suggest that pharmacological treatment of ADHD is cost-effective.

Individuals with untreated ADHD, their families and other caregivers must be made aware of the impact this disorder may have on them at every stage of life and, correspondingly, the improved outcomes that can be achieved with the successful management of ADHD.

\section{Diagnosis and clinical characteristics}

The core triad of ADHD is a persistent pattern of inattention or hyperactivity-impulsivity that interferes with functioning. This is accompanied by associated behavioural, cognitive, emotional and social problems which can lead to workrelated and interpersonal difficulties (see Box 1 for The Diagnostic and Statistical Manual of Mental Disorders (fifth edition) (DSM-5) criteria for ADHD). ${ }^{36}$

Inattention manifests behaviourally in ADHD as difficulty sustaining focus, wandering off tasks, lacking persistence, paralysing procrastination, poor time management, inefficiency and being disorganised.

Hyperactivity refers to excessive motor activity when it is not appropriate or excessive fidgeting, tapping or talkativeness. In adults, hyperactivity may manifest as extreme restlessness 
A. A persistent pattern of inattention and hyperactivity-impulsivity that interferes with functioning or development, as characterised by (1) and (2):

1. Inattention: Six (or more) of the following symptoms have persisted for at least 6 months to a degree that is inconsistent with developmental levels and negatively impacts directly on social and academic or occupational activities:

Note: The symptoms are not solely a manifestation of oppositional behaviour, defiance, hostility or failure to understand tasks or instructions. For older adolescents and adults (age 17 years and older), at least five symptoms are required:

- Often fails to give close attention to details or makes careless mistakes in schoolwork, at work or during other activities (e.g. overlooks or misses details, work is inaccurate).

- Often has difficulty sustaining attention in tasks or play activities (e.g. has difficulty remaining focused during lectures, conversations or lengthy reading).

- Often does not seem to listen when spoken to directly (e.g. mind seems elsewhere, even in the absence of any obvious distraction).

- Often does not follow through on instructions and fails to finish schoolwork, chores or duties in the workplace (e.g. starts tasks but quickly loses focus and easily side tracked).

- Often has difficulty organising tasks and activities (e.g. difficulty managing sequential tasks; difficulty keeping materials and belongings in order; messy, disorganised work; has poor time management; fails to meet deadlines).

- Often avoids, dislikes or is reluctant to engage in tasks that require sustained mental effort (e.g. schoolwork or homework; for older adolescents and adults, preparing reports, completing forms and reviewing lengthy papers).

- Often loses things necessary for tasks or activities (e.g. school materials, pencils, books, tools, wallets, keys, paperwork, eyeglasses and mobile telephones).

- Is often easily distracted by extraneous stimuli (for older adolescents and adults, may include unrelated thoughts).

- Is often forgetful in daily activities (e.g. doing chores, running errands; for older adolescents and adults, returning calls, paying bills and keeping appointments).

2. Hyperactivity and impulsivity: Six (or more) of the following symptoms have persisted for at least 6 months to a degree that is inconsistent with developmental levels and negatively impacts directly on social and academic or occupational activities:

Note: The symptoms are not solely a manifestation of oppositional behaviour, defiance, hostility or a failure to understand tasks or instructions. For older adolescents and adults (age 17 years and older), at least five symptoms are required.

- Often fidgets with or taps hands or feet or squirms in seat.

- Often leaves seat in situations when remaining seated is expected (e.g. leaves his or her place in the classroom, in the office or other workplace or in other situations that require remaining in place).

- Often runs about or climbs in situations where it is inappropriate. (Note: In adolescents or adults it may be limited to feeling restless.)

- Often unable to play or engage in leisure activities quietly.

- Is often 'on the go', acting as if 'driven by a motor' (e.g. is unable to be or uncomfortable being still for extended time, as in restaurants or meetings; may be experienced by others as being restless or difficult to keep up with).

- Often talks excessively.

- Often blurts out an answer before a question has been completed (e.g. completes people's sentences; cannot wait for his or her turn in conversation).

- Often has difficulty waiting his or her turn (e.g. while waiting in line).

- Often interrupts or intrudes on others (e.g. butts into conversations, games or activities; may start using other people's things without asking or receiving permission; for adolescents and adults, may intrude into or take over what others are doing).

B. Several inattentive or hyperactive-impulsive symptoms were present prior to 12 years of age.

C. Several inattentive or hyperactive-impulsive symptoms are present in two or more settings (e.g. at home, school or work, with friends or relatives, in other activities).

D. There is clear evidence that the symptoms interfere with or reduce the quality of social, academic or occupational functioning.

E. The symptoms do not occur exclusively during the course of schizophrenia or another psychotic disorders and are not better explained by another mental disorders (e.g. mood disorder, anxiety disorder, dissociative disorder, personality disorder, substance intoxication or withdrawal).

Source: American Psychiatric Association (APA) ${ }^{36}$

or wearing others out with their activity, being a workaholic, excessive talkativeness, being overscheduled and feeling overwhelmed.

Impulsivity refers to hasty actions that occur in the moment without forethought and could have a high potential for harm to the individual. This may reflect reward dependence and a need for immediate gratification. Impulsive behaviours may manifest as social intrusiveness, a low frustration tolerance, mood lability and losing one's temper, making important decisions without consideration of long-term consequences (e.g. taking a job without adequate information, or impulsively quitting a job, ending relationships, or driving too fast) and addictive behaviours.

These core symptoms should be evident since childhood, with evidence of several symptoms being present since before the age of 12 years. Also, substantial symptoms causing significant impairment should be present in more than one setting (e.g. home, school and work). Some of the impairments related to adult ADHD include job failure or under-employment, complications such as drug dependence, driving accidents, unwanted pregnancies and sexually transmitted diseases, and even a life of perpetual failure.

Typically, symptoms vary depending on context within a given setting. Adult recall of childhood symptoms tends to be unreliable. Confirmation of the presence of symptoms and the impact thereof across various settings typically cannot be done accurately without consulting informants who have seen the individual in those settings. Obtaining collateral information is therefore beneficial - if not crucial.

Symptoms often appear to decrease over time - in number and in severity. However, adults are often more adept at managing these symptoms. Some adults compensate for ADHD-related impairment by choosing lifestyles and careers that suit them. Although they may appear to function well, high amounts of energy and time are used to accomplish tasks.

A field trial in a representative large sample $(N=4000)$ of 18-19-year-old adults ${ }^{14,15}$ indicated a $27 \%$ increase (from $2.8 \%$ to $3.55 \%$ ) in the expected prevalence of ADHD when comparing DSM-IV to DSM-5 criteria. However, the study supported lowering the symptomatic threshold for 
diagnosing ADHD in adults, with the best symptomatic cutoff in the number of symptoms for predicting impairment being five symptoms of inattention and four symptoms of hyperactivity-impulsivity.

Based on these criteria, three types of ADHD are identified:

1. ADHD combined type: If both criteria $1 \mathrm{~A}$ and $1 \mathrm{~B}$ are met for the past 6 months

2. ADHD predominantly inattentive type: If criterion $1 \mathrm{~A}$ is met, but criterion $1 \mathrm{~B}$ is not met for the past 6 months

3. ADHD predominantly hyperactive-impulsive type: If criterion $1 \mathrm{~B}$ is met, but criterion $1 \mathrm{~A}$ is not met for the past 6 months.

Further distinctions are made with regard to severity:

- Mild: Few, if any, symptoms in excess of those required to make the diagnosis are present, and symptoms result in no more than minor impairments in social or occupational functioning.

- Moderate: Symptoms or functional impairment between 'mild' and 'severe' are present.

- Severe: Many symptoms in excess of those required to make the diagnosis, or several symptoms that are particularly severe are present, or the symptoms result in marked impairment in social or occupational functioning.

A course specifier for partial remission is specified where full criteria were previously met, fewer than the full criteria have been met for the past 6 months, and the symptoms still result in impairment in social, academic or occupational functioning. Furthermore, provision has been made for patients who present with symptoms characteristic to ADHD that cause clinically significant distress or impairment in social, occupational or other important areas of functioning predominate but do not meet the full criteria for ADHD. This is done by recording 'other specified attention-deficit/hyperactivity disorder' followed by the specific reason ('with insufficient inattention symptoms'). If the clinician chooses not to specify the reason for partial fulfilment of criteria, or when there is insufficient information to make a more specific diagnosis, the diagnosis will be 'unspecified attention-deficit/hyperactivity disorder'.

\section{Assessment}

Recognition of adult ADHD as a chronic disorder which needs chronic treatment is crucial. ADHD is a clinical diagnosis, which should only be made by a specialist psychiatrist, paediatrician or other healthcare professional with training and expertise in the diagnosis of ADHD. Adults with suspected ADHD whom have previously been diagnosed with ADHD during childhood with symptoms suggestive to ongoing ADHD can consult general adult psychiatric service for confirmation of diagnosis and ongoing treatment. Adults with suspected ADHD without previous diagnosis during childhood should be assessed by a specialist psychiatrist with adequate training and experience in assessments of adults with suspected ADHD for confirmation of diagnosis and treatment initiation. ${ }^{37}$
It is important to consider the history of presenting complaints, but also to use (semi-)structured interviews, rating scales, school- or work-related assessments, social functioning assessments and collateral information in the diagnosis of the disorder.

\section{Screening}

Commonly used rating scales for screening adult ADHD include the World Health Organisation Adult ADHD SelfReport Scale (ASRS) Symptom Checklist, ${ }^{38}$ the Barkley adult ADHD rating scale ${ }^{39}$ the Brown ADD Scale Diagnostic Form (BADDS) ${ }^{40}$ the ADHD Rating Scale, ${ }^{41}$ the Conner's Adult ADHD Rating Scale (CAARS) (DSM-IV), ${ }^{42}$ the Wender Utah Rating Scale (WURS), ${ }^{43}$ and the Wender-Reimherr Adult Attention Deficit Disorder Scale. ${ }^{44}$ The WHO ASRS is the best researched, and the shortened 6-item version has a sensitivity of $68.7 \%$ and specificity of $99.5 \%$ with total classification accuracy of $97.9 \%$ evaluated using population survey data. However, specificity of this and other screening tools may be lower within clinical samples with high rates of other mental health disorders, and positive screens should always be followed by full diagnostic evaluations based on clinical interview data.

\section{Clinical evaluation}

The clinical interview is one of the cornerstones of the assessment process in diagnosing adult ADHD. Although various standardised, structured interviews and rating scales are available, these cannot replace the clinical assessment, but can add some rigor, standardisation and a quantifiable dimension to the areas being evaluated.

For the main diagnostic assessment, the use of the following structured diagnostic interviews may be considered: the Brown Adult ADHD Diagnostic Interview, ${ }^{40}$ the Conners Adults ADHD Diagnostic Interview for DSM-IV (CAADID), ${ }^{45}$ or the Diagnostic Interview for ADHD in adults (DIVA). ${ }^{46}$

A thorough interview is needed, documenting present symptoms and functionality across all spheres of the patient's life. An assessment of the following would be essential: exploring the presence of the core symptoms of ADHD (inattention, hyperactivity and impulsivity), establishing the pervasiveness thereof throughout the individual's lifespan and across different settings (work, school and social domains) and the presence of significant functional impairment throughout the lifespan and across different settings. It has to be noted that the expression of ADHD in adults differs to some extent from that in children, and the diagnostic descriptions of some of the features need to be adapted to adult expression of the disorder (physical over-activity in childhood could be replaced in adulthood by constant mental activity, feelings of restlessness and difficulty engaging in sedentary activities). The Barkley Functional Impairment Scale for adults ${ }^{39}$ and the Weiss Functional Impairment Rating Scales (WFIRS) ${ }^{47}$ are useful measures to assess the impact of symptoms on clinically relevant domains of functioning. 
Differential diagnoses (e.g. a lack of effort, poor vocational match, or transient situational or environmental circumstances) and other psychiatric or medical diagnosis (and treatment thereof) that can explain the symptoms should be excluded. Furthermore, a thorough evaluation for the presence of comorbid psychiatric disorders (including substance use) is essential.

Comorbidity in individuals with adult ADHD is very common. Comorbid disorders can be the presenting problem in many adults and is a confounding factor in the diagnosis of ADHD, with a negative impact on treatment decisions and response. International studies indicated that the majority of adults with ADHD have complicating and clinically significant comorbid psychopathology, with more than one psychiatric disorder in up to $87 \%$, whereas at least $57 \%$ of individuals have more than two psychiatric disorders.

In a South African database analysis, ${ }^{19}$ psychiatric comorbidity was also more prevalent in individuals with adult ADHD than in the general population for both anxiety disorders $(13.1 \%$ vs. $8.1 \%)$ and mood disorders ( $13.8 \%$ vs. $4.5 \%)$. The presence of adult ADHD also more than tripled the prevalence of multiple comorbidity $(9.09 \%$ vs. 3.9\%). The most common psychiatric comorbidities were adjustment disorders in $29.5 \%$ of patients with comorbid psychiatric conditions $(2.7 \%$ of the sample), followed by non-organic sleep disorders in $19.4 \%$ (1.8\% of the sample) and anxiety disorders in $13.1 \%$ (1.2\% of the sample). Mood disorders occurred as comorbid disorders in $13.8 \%$ of the patients $(1.2 \%$ of the sample), whereas substance-related disorders occurred in $2.3 \%$ of adults with $\operatorname{ADHD}(0.2 \%$ of the sample).

In clinical psychiatric practice settings, ${ }^{19}$ psychiatrists indicated the presence of comorbid disorders in patients with adult ADHD as follows: anxiety disorders in $40.33 \%$ (the most prevalent being generalised anxiety disorder), SUD in $33.81 \%$ (with alcohol abuse being the most common substance of choice), major depressive disorder in $33.28 \%$ and bipolar mood disorder in $13.75 \%$. Personality disorders as a group (mostly cluster B) were present in $28.26 \%$ of patients with adult ADHD.

Although a diagnosis based only on self-report is possible, such an approach may lead to an under- or over-diagnosis of ADHD, and it may be more reliable to obtain collateral information from other sources. Whenever possible, corroborating information should be obtained from a living parent, or older relative for childhood behaviour and a partner, relative or close friend for current behaviour and symptoms. This should include additional information on developmental and family history. Although Breda et al. ${ }^{48}$ found that collateral report has no incremental value in the evaluation of childhood ADHD symptoms in adults with a self-reported history of ADHD assessed in clinical settings, obtaining collateral information from parents on childhood ratings protect against possible student and adult malingering to obtain ADHD medications or accommodations. ${ }^{49}$

\section{Medical, laboratory and other special examinations}

It is important that each patient should have a thorough medical evaluation which would include a complete medical history and comprehensive physical examination with the purpose of excluding causative or comorbid medical disorders, and a baseline safety assessment. The minimum requirements are the documentation of vital signs, weight and height. Screening for visual and auditory deficits or processing and integration problems should be considered and appropriate referrals to specialist optometrists and speech and language pathologist considered. Special examinations are a significant cost-driver in the management of ADHD and should not be requested routinely. ECGs should be requested in any patient with personal or familial cardiac risk factors. Liver function tests should be requested in patients with a history of liver disease prior to initiating treatment with atomoxetine. A comprehensive neurological examination should be considered if any symptoms suspicious of neurological disorders, including head injuries or symptoms of epilepsy, are present, with an appropriate referral to a neurologist or for an EEG where indicated. There are at present insufficient data for the use of brain imaging modalities in the diagnosis of adult ADHD. Although the US Food and Drug Administration (FDA) has approved an electroencephalogram-based instrument as a diagnostic aid, demonstrating higher resting theta:beta waves, for ADHD in children (as part of a complete medical and psychological evaluation), there is currently no evidence for the use thereof in the diagnosis of adults with ADHD. ${ }^{50}$ Brain mapping, event-related potentials and neuroimaging are also of limited clinical use. It lacks diagnostic specificity, is costly and is not readily available.

\section{Psychometric evaluation}

There are currently no neuropsychological tests for ADHD with sufficient sensitivity and specificity to serve as an

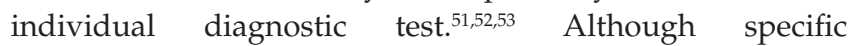
neuropsychological tests, especially those examining executive dysfunction, can be useful, it should not be used in isolation as a diagnostic tool in the absence of a comprehensive clinical evaluation by an experienced clinician, but as complementary to diagnostic assessments in order to determine individual deficits and to suggest individualised interventions. ${ }^{54}$ Current neuropsychological tests based solely on executive function are of limited value, whereas multi-domain assessments and computerised assessments (the Quantified Behavioural Test QbTest), ${ }^{55}$ the MOXO $\mathrm{d}-\mathrm{CPT}^{56}$ and the Test of Variable of Attention (TOVA ${ }^{57}$ have not yet established utility and cost-effectiveness.

Neuropsychological assessments should be considered when the functional impairment the patient is experiencing is more than what would be expected from the core symptoms alone. Neuropsychological testing is also useful to supplement core treatment in the development of personalised treatment approaches and interventions for educational or work 
purposes, as well as monitoring treatment response and identifying areas which may need further interventions, but should not be used to establish treatment response..$^{50}$

Sensitive use of general intelligence tests can be useful to ascertain potential attainment and to diagnose co-morbid learning disabilities for educational interventions. ${ }^{53}$ Appropriate referral to an educational psychologist should be considered.

Interest, reward and educational achievement are important complicating factors during the assessment of ADHD. A significant percentage of those making suspect effort during neuropsychological evaluation will be diagnosed with ADHD using the most commonly employed assessment methods: interview alone (71\%), interview and behaviour rating scales combined (65\%) and an interview, behaviour rating scale and Continuous Performance Test (CPT) test combined $(57 \%)$. It is therefore essential to evaluate task engagement and possible symptoms amplification during clinical evaluation. ${ }^{58}$

\section{Treatment}

\section{Treatment goals}

According to the $\mathrm{WHO}^{59}$ mental health is 'a state of wellbeing in which every individual realises his or her own potential, can cope with the normal stresses of life, can work productively and fruitfully, and is able to make a contribution to her or his community'. The initial goal of any intervention is therefore symptoms relief, followed by ongoing alleviation of symptoms accompanied by decreasing functional impairment and working towards optimal functioning. This will include the prevention and treatment of comorbid disorders, relapse prevention and the improvement of the quality of life of patients and their families.

\section{General aspects of treatment}

As highlighted by the British Association for Psychopharmacology (BAP) guidelines, ${ }^{50}$ Maudsley guidelines $^{60}$ and Schoeman, ${ }^{19}$ a comprehensive assessment and diagnostic certainty prior to initiating pharmacological treatment is crucial and treatment should be initiated at specialist level.

Good long-term clinical care is contingent on adequate patient education about the nature of the disorder and effects of treatment. Once the diagnosis has been confirmed, clinicians should provide sufficient information to empower patients to make informed decisions with regard to treatment options and designing interventions that meet the patient's individual needs.

Pharmacotherapy remains the cornerstone of treatment. Contrary to the treatment of ADHD in children, pharmacological interventions are always first line in adults - based on the lack of efficacy of non-drug intervention in the absence of medical treatment. ${ }^{60}$ Drug treatment should be continued as long as clinically effective and should be reviewed at least annually. Effects of missed doses, planned dose reductions and periods of non-treatment should also be evaluated. ${ }^{50}$

Although pharmacotherapy plays a primary role in the treatment of ADHD, psychosocial interventions form an integral part of a comprehensive, multi-modal, management approach for adults with ADHD. Meta-analysis and systematic reviews have confirmed the superiority of combination (pharmacological and psychosocial) interventions. A multi-modal approach is also encapsulated in international guidelines (e.g. BAP and National Institute for Health and Care Excellence (NICE)) which recommend psychosocial treatments as complementary to psychopharmacological interventions to provide support, improve acceptance of diagnosis, and treat comorbidities and residual symptoms (which do not require additional psychopharmacological treatments).

\section{Cost-effectiveness of treatment}

Few economic evaluation studies could be traced - all of them cost-effectiveness studies in children with ADHD. In a costeffectiveness study, costs are related to a single common effect that may differ in magnitude between the alternative options or programmes ${ }^{61}$ (i.e. comparing treatment option A with treatment option B with regard to a certain outcome measure).

The first cost-effectiveness study in children with ADHD dates back to $2005 .{ }^{62}$ In this study, 579 children with ADHD were assigned to 14 months of medication management, behavioural treatment, both combined or community care. Services were tallied throughout the study, including medication, healthcare visits, behavioural treatments and rental costs. Provider specialty, total time and number of visits with providers were used to calculate costs, adjusted to FY 2000 dollars with the consumer price index. The authors found that treatment costs varied fourfold, with psychopharmacological management being the least expensive, followed by behavioural treatment, and then combined treatment. They concluded that medication only, although not as effective as combined treatment, is likely to be more cost-effective in routine treatment for children with ADHD.

Wu, Hodgkins, Ben-Hamadi, et al. ${ }^{63}$ did a systematic literature review of 13 economic evaluations of pharmacotherapies for children and adolescents with ADHD conducted between 1990 and 2011 in North America, Europe, Australia or New Zealand. Therewas consistentevidence that pharmacotherapies are cost-effective compared with no treatment or behavioural therapy. However, the data were not comprehensive enough to draw conclusions regarding the relative cost-effectiveness of different pharmacological agents.

\section{Pharmacological treatment}

The first evidence for the effectiveness of stimulants in the treatment of ADHD dates back to 1937, when Bradley 
conducted a trial with Benzedrine in children with ADHD. ${ }^{64}$ The first double-blind placebo controlled trial in ADHD examining the efficacy of Dexedrine was done in $1967 .{ }^{65}$ Since then, many studies have been conducted and established the efficacy of both stimulant- and non-stimulant medications in the treatment of ADHD in children and adolescents, and more recently also in adults. Consistent with the catecholamine hypotheses of ADHD, the drugs that effectively treat the disorder are known to modulate catecholamine pathways.

Medications used in the treatment of ADHD include psychostimulants [e.g. methylphenidate (MPH) and amphetamines] and non-stimulants [e.g. atomoxetine, alpha ${ }_{2}$-adrenoceptor agonists (clonidine and guanfacine), tricyclic antidepressants (TCAs), bupropion, modafinil and venlafaxine]. Enhancement of dopaminergic and noradrenergic neurotransmission in the prefrontal cortex is probable critical to the therapeutic efficacy of ADHD medication $^{66}$ (see Table 1 for the pharmacological classification of medication used for the treatment of ADHD).

Although pharmacotherapy plays a primary role in the treatment of ADHD, psychosocial interventions [psychoeducation, cognitive behavioural therapy (CBT), supportive coaching or assistance with daily activities] are an integral part of management. Discussions on clinical efficacy are limited by the lack of head-to-head studies with adequate and unbiased methodology. In general, dopaminergic and noradrenergic agents can reduce the core symptomatology, though specific effects and side effects may vary between agents. Treatment choice would therefore also depend on factors such as patient preference and comorbid conditions, abuse potential, side effect profile and toxicity in overdose.

In terms of treatment, stimulants are by far the best studied (and most effective) treatment for ADHD across the lifespan. ${ }^{67}$ The three stimulants - MPH, pemoline (withdrawn from the market because of liver toxicity) and dextroamphetamine have similar effects, with an average response rate of $70 \%{ }^{8}$

\section{Methylphenidate (Ritalin ${ }^{\circledR}$ IR \& LA, Concerta ${ }^{\circledR}, \mathrm{HCL}$ Douglas-methylphenidate ${ }^{\circledR}$ )}

Various controlled studies have confirmed the effectiveness of $\mathrm{MPH}$ in about $57 \%$ of adults with ADHD. ${ }^{68}$ Meta-analyses of $\mathrm{MPH}$ in adults demonstrate similar drug response rates and effect sizes to those seen in children, although slightly lower. For direct comparison with placebo, effect sizes were calculated as 0.9 in favour of $\mathrm{MPH} .{ }^{69}$ In a recent metaregression analysis of 18 studies (2045 patients), ${ }^{70} \mathrm{MPH}$, at a mean dose of $57.4 \mathrm{mg} /$ day, had a moderate effect on ADHD symptoms compared with placebo [standard mean difference
(SMD) 0.57-0.58]. MPH improved ADHD symptoms in adults in a dose-dependent fashion, with an increase in efficacy (SMD 0.11-0.12) for every $10 \mathrm{mg}$ increment of MPH. In another systematic review and indirect comparison metaanalysis of 22 placebo-controlled trials of 2203 adults with $\mathrm{ADHD},{ }^{71}$ conventional shorter-acting stimulants had a more favourable risk-benefit ratio than longer-acting stimulants and non-stimulants in adults. Short-acting stimulants also reach effect sizes of 4.32 versus an effect size of 1.35 for longacting stimulants.

In addition to reducing the core symptoms of ADHD, stimulants improve associated features of ADHD, such as ontask behaviour, academic performance and social functioning. These effects appear to be dose-dependent and are evident across settings. In adults, emotional regulation, occupational problems and marital discord also tend to be reduced on treatment. Side effects (headache, reduced appetite, palpitations, nervousness, initial insomnia and dry mouth) are usually mild and transitory. ${ }^{67}$

The BAP guidelines ${ }^{50}$ and the NICE guidelines ${ }^{37}$ recommend stimulants, specifically MPH as the first-line treatment choice in adults. The European Network Adult ADHD (ENAA) consensus statement ${ }^{67}$ specifically recommends the use of extended release stimulants as treatment of choice for adults with ADHD. Long-lasting, extended-release formulations are preferred because of non-adherence, a lower abuse potential, fewer rebound symptoms and frequent dosing with shortacting formulations. The Maudsley guidelines recommend the use of modified-release MPH (because of the convenience of single-day dosage - therefore improving adherence) or multiple doses of immediate-release (greater flexibility in controlling time course of action and closer initial titration) as the second-line treatment for adults with ADHD. The Canadian ADHD Practice (CAP) Guidelines indicates amphetamine mixed salts (not available in SA), MPH OROS ${ }^{\circledR}$ technology and atomoxetine as the first-line treatments, whereas other MPH preparations are considered second-line options. $^{72}$

Currently, combinations of immediate and extended release preparations are often prescribed in adults - where the immediate release formulations are used as 'top-up' when the extended release formula is wearing off. The dose of stimulants should be individually adjusted, based on efficacy and tolerability - with a general recommended dose of $1 \mathrm{mg} /$ $\mathrm{kg} .{ }^{73}$ The range of half-lives of medications suggest that it is more practical to consider maximum dose in terms of the maximum taken at each time point, the length of effect of each dose on the control of ADHD symptoms and the number

TABLE 1: Pharmacological classification of medication used for the treatment of ADHD.

\begin{tabular}{llll}
\hline Neurotransmitter & Mechanism of action & \\
\hline Noradrenaline selective & Noradrenaline and dopamine & Monoamine reuptake inhibitors & Monoamine releasing agents \\
Atomoxetine & $\begin{array}{l}\text { Methylphenidate } \\
\text { d-amphetamine } \\
\text { Lisdexamphetamine }\end{array}$ & Atomoxetine & $\begin{array}{l}\text { d-amphetamine } \\
\text { Lisdexamphetamine }\end{array}$ \\
\hline
\end{tabular}

Source: Dvorsky et al. ${ }^{49}$ 
of doses required to provide sufficient control throughout the day - rather than a maximum based on $\mathrm{mg} / \mathrm{kg}$ per day. ${ }^{67}$

\section{Lisdexamphetamine (Vyvanse ${ }^{\circledR}$ )}

Lisdexamphetamine is a prodrug metabolised by red blood cells to yield its active metabolite, $\mathrm{d}$-amphetamine and L-lysine. ${ }^{74}$ A number of randomised, double-blind, placebo-controlled trials and open-able long-term studies have confirmed efficacy and tolerability for adults with $\mathrm{ADHD}_{,}^{75,76,77}$ whereas a metaanalysis confirmed an effect size of $0.8{ }^{70}$ Furthermore, Jasinski and Krishnan ${ }^{78}$ documented a lower liability for recreational abuse - which would position this drug as one of the treatments of choice for patients with a dual diagnosis of ADHD and a substance abuse disorder. The NICE guidelines ${ }^{37}$ recommends dexamphetamine as the second-line treatment for adults who develop intolerable side effects to MPH. Common side effects of lisdexamphetamine include insomnia and irritability, whereas dizziness, appetite suppression with weight loss, headache and other gastrointestinal side effects have also been reported. There have been post-marketing reports of psychosis, aggression, depression, exacerbation of tics and cardiovascular side effects such as palpitations, hypertension and myocardial infarction with sudden death.

\section{Atomoxetine (Strattera ${ }^{\circledR}$ )}

For adults who do not respond to stimulant treatment or who have a condition in which a stimulant is contra-indicated, the non-stimulant atomoxetine is an appropriate alternative. ${ }^{67}$ The BAP guidelines ${ }^{50}$ and Maudsley guidelines ${ }^{60}$ recommend atomoxetine as the first-line treatment in patients with comorbid SUD and as the treatment of choice in patients with comorbid anxiety disorders, severe tics or when there is a risk of diversion of medication. The NICE guidelines ${ }^{37}$ as well as ENAA ${ }^{67}$ considers atomoxetine as a second-line agent for patients with insufficient response to, or those who cannot tolerate $\mathrm{MPH}$.

In a meta-analysis of atomoxetine in the treatment of ADHD in children and adolescents, non-stimulants had a significant lower effect size than those of short-acting and long-acting stimulants $\left(0.39,0.96\right.$ and 0.73 respectively). ${ }^{79}$ However, in a meta-analysis comparing pharmacotherapeutic options in adults with ADHD, the effect size of atomoxetine was 0.59 versus an effect size of 0.67 for stimulants. However, in a recent systematic review, ${ }^{80}$ criticism against previous studies was raised. When the duration of studies was increased, and treatment naïve patients analysed separately, the effect size of atomoxetine improved to 0.9 , which is very similar to the effect size of 1.0 of MPH. In SA, atomoxetine is still being underutilised ${ }^{19}$ - which may be a reflection of lack of knowledge and experience with regard to efficacy and effectiveness. It may also reflect patients' preference for a medication which leads to immediate results - which stimulants provide.

Side effects of atomoxetine appear reflective of increased noradrenergic tone and include dry mouth, insomnia, nausea, decreased appetite, constipation, decreased libido, dizziness, sweating and rare cases of hepatotoxicity. ${ }^{81}$

\section{Other agents}

Although other drugs such as clonidine, guanfacine, TCAs, modafanil and venlafaxine are mentioned in international guidelines as the third-line treatment for ADHD, ${ }^{50,67,72}$ none of these are registered for the treatment of adult ADHD in SA and use will be off-label - at the discretion of the treating physician. Anticonvulsants, mood stabilisers, selective serotonin reuptake inhibitors and antipsychotic drugs have not been shown to be effective for primary symptoms of ADHD. They may, however, be useful in treating some comorbid conditions that patients with ADHD have.

$\alpha_{2}$-noradrenergic agonists: Clonidine (Dixarit $\left.{ }^{\circledR}\right)$ has demonstrated efficacy in childhood ADHD, especially for cases marked by severe hyperactivity and aggression. ${ }^{82}$ However, there is an absence of literature on efficacy and tolerability in adults with ADHD.

Results from clinical trials have demonstrated efficacy for guanfacine (not available in SA) in combined (hyperactiveimpulsive-inattentive) ADHD in children and adolescents, but it appears to be less effective in the inattentive subtype of ADHD. The response rate in children was 50\% - 60\%. ${ }^{83,84}$ In adults, the effect size was comparable to placebo. ${ }^{85}$ Potentially problematic side effects include hypotension, bradycardia, dizziness, somnolence, sedation, fatigue, dry mouth, nausea and abdominal pain. Guanfacine is the only ADHD medication which is associated with moderate weight gain.

Tricyclic antidepressants: Most studies of TCAs found a moderate to robust reduction in ADHD symptomatology in children with a moderate to strong treatment effect. The more selective noradrenergic drugs, that is, imipramine (Ethipramine ${ }^{\circledR}$, Tofranil $\AA$ ) and the active metabolite desipramine, are more effective and better tolerated. A target dose of $200 \mathrm{mg}$ / day is indicated. TCAs have negligible abuse liability and efficacy for comorbid anxiety and depression. ${ }^{86}$

Modafanil (Provigil@): Although efficacy for this wakepromoting drug in the treatment of ADHD in children has been demonstrated, ${ }^{87}$ studies in adults failed to demonstrate efficacy in reducing ADHD symptoms..$^{88,89}$

Selective serotonergic and noradrenergic reuptake inhibitors: Venlafaxine (e.g. Effexor ${ }^{\circledR}$, Venlor $\left.{ }^{\circledR}\right)$ appears to be mildly efficacious in moderating ADHD symptom, with studies indicating a measurable reduction in symptoms at doses of $75 \mathrm{mg} /$ day $-150 \mathrm{mg} /$ day. ${ }^{5,90,91}$

Noradrenergic dopaminergic reuptake inhibitors: Bupropion hydrochloride (Wellbutrin ${ }^{\circledR}$ ) has demonstrated moderate effect in the treatment of ADHD with a $42 \%$ reduction in ADHD rating, with $52 \%$ of subjects considered responders at a mean dose of $362 \mathrm{mg} /$ day. ${ }^{92,93,94,95}$ Dosing appears to be optimal at $400 \mathrm{mg} /$ day $-450 \mathrm{mg} /$ day and there is a delay in onset of action. In a meta-analysis ${ }^{96}$ found the number needed to treat 4.6 with a discontinuation rate no higher than placebo. In a systematic search of studies, 
Peterson, McDonagh and $\mathrm{Fu}^{71}$ found the pooled effect size for bupropion to be 1.87. Side effects include insomnia, edginess and a low risk for seizures. Bupropion should be considered in adults with comorbid mood disorders (depression or bipolar disorder) or SUD.

Monoamine oxidase inhibitors: Some studies $^{97,98}$ have suggested effectiveness of monoamine oxidase inhibitors (such as pargyline, deprenyl and selegiline) in the treatment of adult ADHD, but their potential to cause hypertensive crisis and the dietary restrictions pertaining to tyraminecontaining foods, seriously limit their use. ${ }^{99,100}$

\section{Non-pharmacological interventions}

\section{Psychotherapy}

Pharmacotherapy alone is not sufficient to stabilise the many problems of adults with ADHD, nor does current research support the efficacy of psychotherapeutic treatments as sole treatment for adult ADHD. ${ }^{68}$ The multimodal treatment study in $\mathrm{ADHD}^{101}$ has confirmed definitive evidence for the beneficial effect of psychotherapeutic interventions in childhood ADHD. However, evidence in adult ADHD is sparse. Various forms of structured, intensive and skills-based treatment may improve the likelihood of attaining remission, especially when combined with medication. ${ }^{53}$ The effects of therapy on the core symptoms of ADHD seem substantial, with potential effects on comorbid symptoms.

The NICE guidelines, ${ }^{37}$ ENAA $^{67}$ and BAP guidelines ${ }^{50}$ recommend $^{2}$ a multi-modal treatment approach with psychosocial treatments as complementary to psychopharmacological interventions to provide support, improve acceptance of diagnosis, and treat comorbidities and residual symptoms (which do not require, or do not tolerate, additional psychopharmacological treatments).

Although different approaches have been used, the majority of evidence is for structured CBT interventions, with modified CBT plus medication demonstrating greater benefits than psychotherapy or medication alone particularly on the core symptoms of ADHD, with lesser effect on anxiety and depression. ${ }^{102,103} \mathrm{CBT}$ strategies are focused on improving the core symptoms of ADHD through self-instructional training and memory aids to improve attention, techniques to reduce impulsivity (e.g. 'stop and think'), diaries and time schedules to improve organisational skills, and assertiveness and social skills training to improve communication skills. Group and individual CBT demonstrated similar outcomes. ${ }^{104}$

Mindfulness awareness therapy is a complementary intervention that not only improves affect and mood regulation in adults with ADHD, but also sustained attention and quality of life. ${ }^{105}$ There is also some evidence for the use of dialectical behaviour therapy, ${ }^{106}$ psychoeducation and organisational skills teaching ${ }^{107}$ and cognitive remediation programmes. ${ }^{108}$ Cognitive remediation provides techniques focussing on retraining cognitive function, teaching internal and external compensatory strategies, and restructuring the physical environment to maximise functioning. However, it is important to note that skills-based therapy and psychodynamic therapy ${ }^{109}$ may have a negative effect on self-esteem.

Formal studies of the effectiveness of coaching and psychoeducation have not been performed, but many adults with AHDD report that they gain benefit from these approached. Coaching is a structured, supportive therapy that can be offered individually or by group sessions. The purpose of coaching is to learn new problem-solving skills for identified practical problems.

It is optimal to pursue an individually tailored problemoriented approach to psychosocial interventions. This may include individual, family, and group therapy, social skills training, occupational therapy and liaison with employees and academic institutions, and coaching.

\section{Neurofeedback}

Neurofeedback (NF) has been investigated as a possible alternative treatment for ADHD in children. ${ }^{110} \mathrm{NF}$ is thought to reduce behavioural problems associated with the core symptoms of ADHD through enabling the patient to acquire skills to self-regulate certain brain activity patterns. In a meta-analysis, large effect sizes for impulsivity and inattention, and a medium effect size for hyperactivity were reported for theta and beta, sensorimotor rhythm and slow cortical potentials (SCP) protocols in ADHD. ${ }^{111}$ A recent study ${ }^{112}$ has evaluated the effectiveness of 30 sessions of SCP NF in 24 adults with ADHD. In this study, significant symptom reduction (self-rated and third-party rated) was observed with medium to large effect sizes after treatment and 6 months post treatment with regard to clinical symptoms, as well as reaction time, reaction time variability and contingent negative variation. Fourteen participants experienced a symptom reduction of over $25 \%$ and symptoms of six participants remitted, that is, they did not meet criteria for an ADHD diagnosis anymore. However, in a systematic review and meta-analyses of randomised controlled trials, ${ }^{113}$ NF did not demonstrate any statistically significant improvement on ADHD measures with blinded assessment in placebo- and non-placebo controlled trials.

\section{Exercise}

A recent meta-analysis investigating the effects of acute exercise on cognitive performance in healthy adults revealed that cognitive performance, particularly executive functioning tasks, was improved after 20 minutes of exercise. ${ }^{114}$ In humans and in animal models, exercise has been found to have wide-ranging cellular, structural, functional and cognitive benefits. These include enhanced frontal lobe volume, executive functioning, brain-derived neurotrophic factor (BDNF) levels, cerebral blood flow, and dopamine and other monoamine modulation. ${ }^{115}$

There is also growing body of research indicating positive effects of acute aerobic activity and longer-term activity on neuropsychological function in ADHD. Existing studies 
examining effects of physical activity on ADHD have generally studied children and adolescents, with some emerging work in adults with ADHD. Studies have shown that in children with ADHD, moderate-to-vigorous physical activity improves planning, and working memory, inhibitory control, novel problem-solving, processing speed and academic performance, ${ }^{116,117,118,119}$ whereas acute high intensity physical activity can improve sustained attention independent of stimulant treatment. ${ }^{120}$

In adults with $\mathrm{ADHD}$, there is preliminary evidence that individuals who report more frequent physical activity experience reduced impulsivity, worry and intrusive thoughts, ${ }^{18}$ whereas acute moderate intensity exercise facilitated performance on executive functioning. ${ }^{121,122}$ Although specific recommendations regarding frequency, intensity or duration of exercise in ADHD have not been established, ${ }^{123}$ there is growing consensus that regular exercise engagement is a powerful nonpharmacological treatment for management of ADHD symptoms and promotion of cognitive health.

\section{Complementary and alternative medications}

In a systematic review and meta-analyses of randomised controlled trials of dietary and psychological interventions, ${ }^{113}$ 2904 published randomised controlled trials of dietary (restricted elimination diets, artificial food colouring exclusion and free fatty acid supplementation) and psychological interventions (attention and working memory training, cognitive training, NF and behavioural interventions) for ADHD were screened. Of these, 54 trials met inclusion criteria for the analysis. Two different analyses were performed: one where the outcome measure based on ADHD assessments was completed by parents or teachers, and the other where the best possible blinded assessments (i.e. placebo- and non-placebo controlled trials where the assessments were made by individual blinded to treatment) of improvement on ADHD measures were included. Although all dietary and psychological interventions produced statistically significant effects, in the latter group only free fatty acid supplementation and artificial food colouring exclusion remained significant. It therefore seems that free fatty acid supplementation produced small but significant reductions in ADHD symptoms even with probably blinded assessments, although the clinical effects of these effects remain to be determined. Artificial food colouring exclusion produced larger effects but often in individuals selected for food sensitivities.

N-3 omega-3 polyunsaturated fatty acids (n-3 PUFAs) are promoted as cognitive enhancers in the general population, as well as for patients with neurocognitive deficits such as ADHD. In a recent systematic review and meta-analysis, ${ }^{124}$ only marginal evidence was found for n-3 PUFA supplementation in those who are n-3 PUFA deficient. No significant benefit was found for the general population, nor those with ADHD.

Although many individuals, with and without ADHD, report benefits from 'brainsmart food' such as mentat, zinc, l-carnitine, vitamin B6, magnesium, ginkgo biloba, ginseng, passionflower, acetyl 1-carnitine(ALCAR), dimethylethanolamine (DMAE), L-theanine, dosahexaenoic acid (DHA), citicoline, curcumin, phosphatidylserine, vincopetine, L-alphaglycerylphosphorylcholine, bacopa monnieri and huperzine A, formal studies of the effectiveness of these agents are lacking. At present, there is no consistent evidence from randomised control trials for the use of any food supplements. ${ }^{67}$

\section{Algorithm}

See Figure 1 and Table 2.

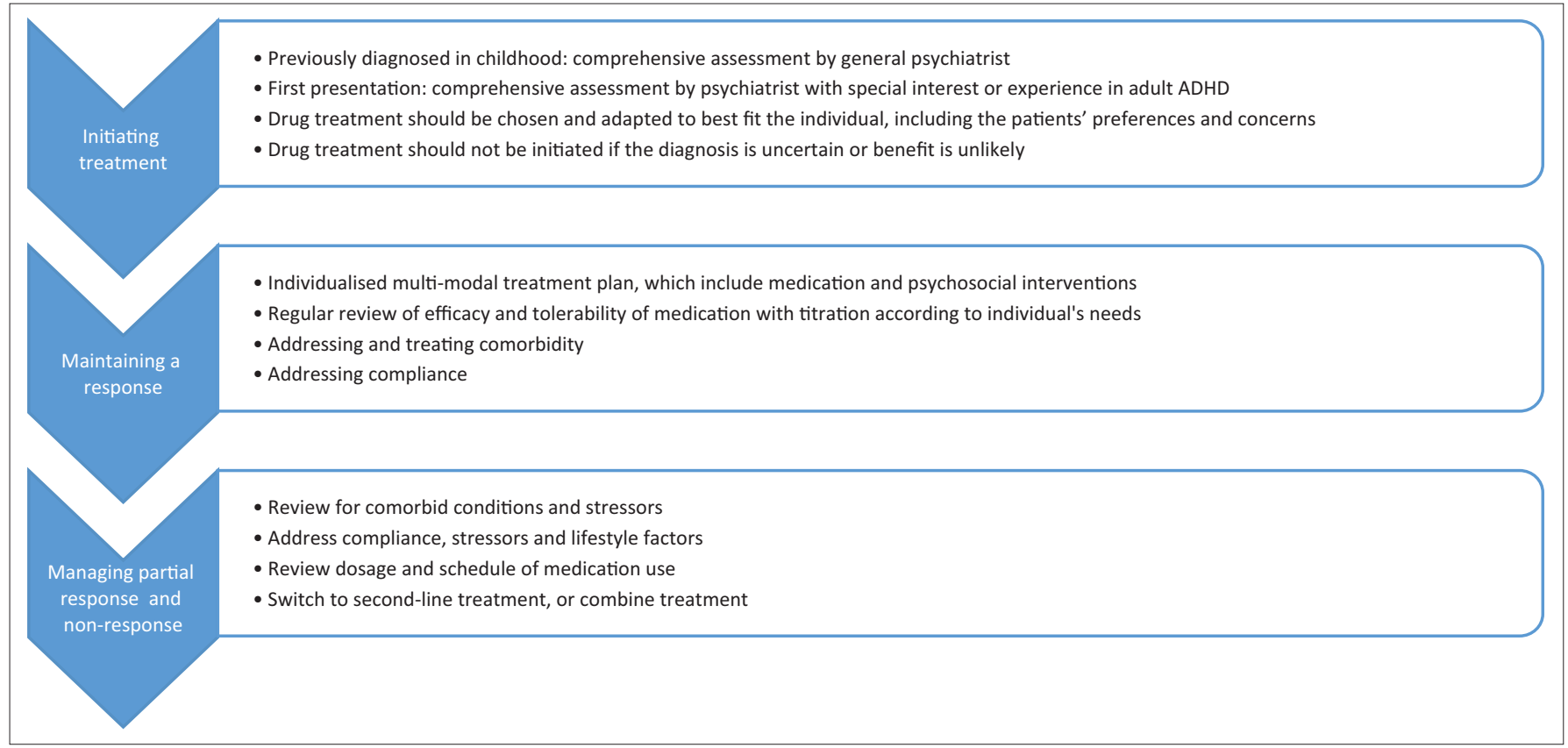

FIGURE 1: Management process. 
TABLE 2: Medication schedule.

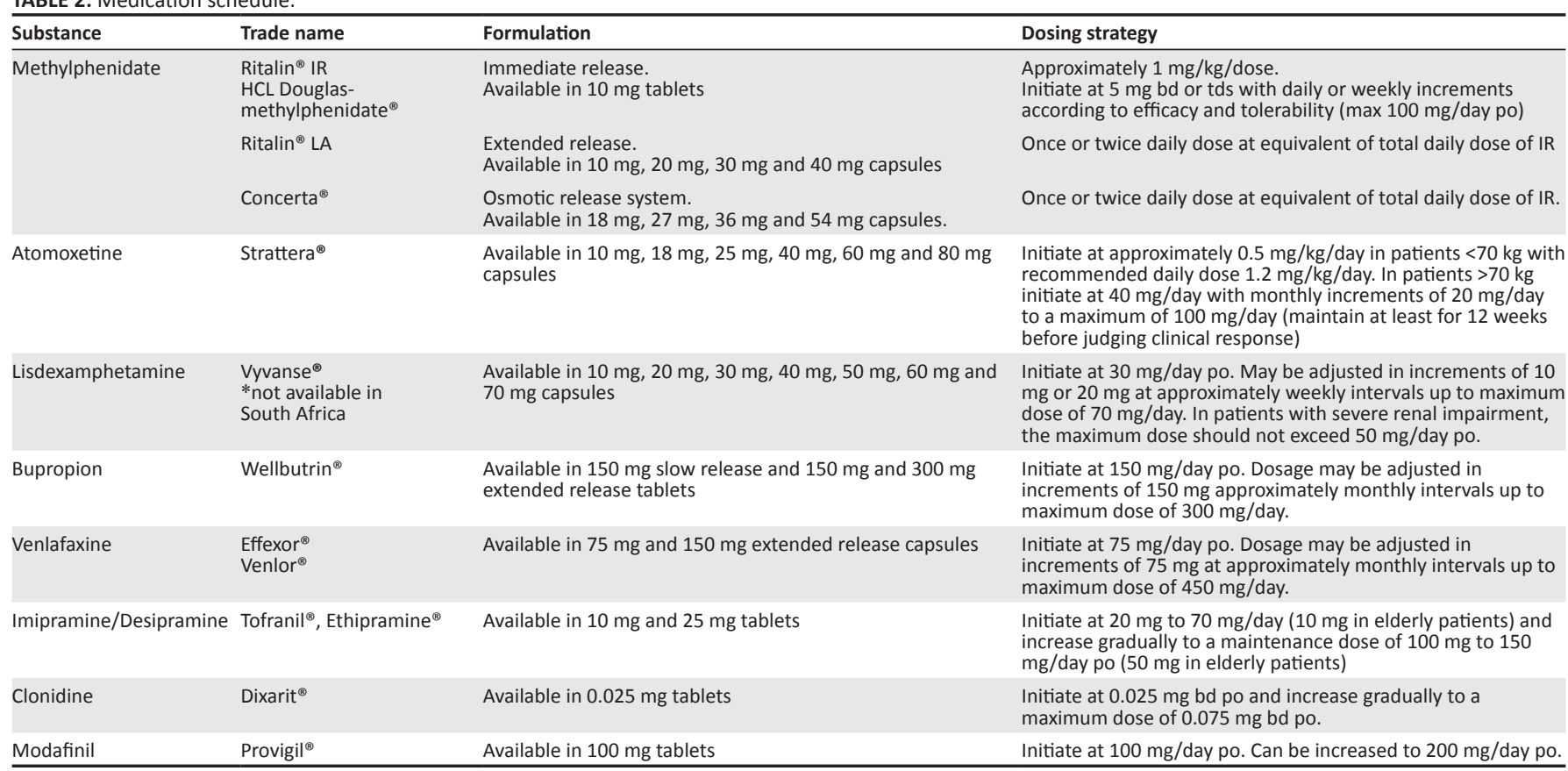

\section{Special populations}

\section{Comorbidity}

The order of treatment of ADHD and comorbid disorders depends on the severity of the different disorders and clinical judgement on which disorder is driving the current level of behavioural impairments or mental state changes. The presence of comorbidity increases the likelihood of the need for combination therapy - both in terms of psychopharmacological agents and psychotherapeutic approaches. In initiating medication for comorbid conditions, an individualised approach with regard to effectiveness, riskbenefit profile and tolerance should be considered.

In the presence of comorbid disorders, a risk assessment should be done. Severe mood disorders, severe anxiety disorders (with panic attacks) and psychotic disorders should be treated prior to treating ADHD. Milder disorders (e.g. mild depression and anxiety) may be deferred until after treatment of ADHD as treating the ADHD might alleviate other symptoms. ${ }^{67} \mathrm{~A}$ sequential approach to initiating medication is recommended. In the case of psychotic disorders or severe bipolar disorders, stimulants should be used with caution.

Patients with ADHD and comorbid SUD often present with more severe SUD characterised by early onset, extended duration of the SUD, greater impairment and shorter transition from substance use to dependence. In cases of comorbid SUD, the SUD can be treated either before initiating treatment for ADHD, or simultaneously. Close supervision is advised when treating ADHD patients with SUD with stimulants and in cases where diversion or abuse is a particular concern, atomoxetine may be selected as the firstline treatment. The concerns of some professionals that use of stimulants in ADHD may lead to drug abuse either by sensitisation or as a gateway to other drugs is not supported by evidence. Long-acting stimulants with a lower abuse potential, lisdexamphetamine and bupropion are preferred over short-acting stimulants. Concomitant psychosocial interventions are crucial.

\section{Pregnancy and lactation}

All the stimulants, atomoxetine, bupropion, modafinil and other pharmacological agents discussed in these guidelines (see section Pharmacological treatment) are considered 'category $C^{\prime}$ by the FDA, that is, animal studies have reported some harm, without having any robust evidence in human studies. ${ }^{125}$ Although continuation of treatment during pregnancy may therefore pose a risk to the child, discontinuation may increase harmful behaviours related to the mother's mental state. ${ }^{50}$ It is therefore important to consider the risk-benefit profile of not treating the mother, for example, poor risk management, dangerous driving, illicit drug use, alcohol and tobacco use, increased levels of distress and self-injurious behaviour. Non-pharmacological strategies should be explored, and liaison with the obstetrician is important.

\section{Summary}

Adult ADHD is a chronic, costly and debilitating disorder - if untreated. Recognition of adult ADHD as a chronic disorder which needs chronic treatment is crucial.

A comprehensive diagnostic assessment and diagnostic certainty prior to initiating drug treatment are crucial. This is not possible during the average 15-min general practitioner consultation, and it is therefore strongly advised that the diagnosis of adult ADHD and treatment initiation should be made by a psychiatrist well versed in the complexities of $\mathrm{ADHD}$ and the comorbidity thereof. Raising the diagnostic 
bar for adult ADHD will also prevent the scripting of medication for patients who use the medication for reasons other than the treatment of ADHD (e.g. cognitive enhancement) which artificially escalates the prevalence and costs of ADHD.

Once a proper treatment plan has been established, and a patient is contained within a multi-disciplinary and multimodal (psychosocial intervention and an optimal medication regime) basket of care, follow-up can take place on primary healthcare level - leading to further cost savings to schemes and reducing pressure on resources (manpower and financial) at specialist level. ${ }^{19}$ Ongoing treatment (which includes compliance to treatment) is crucial in preventing complications and long-term costs.

\section{Acknowledgements}

Dr Schoeman serves on the pharmaceutical advisory boards of Lundbeck, Adcock and Lilly. She has received honoraria, sponsorships and speakers' fees from Janssen, Lundbeck, Cipla, Servier, Sanofi/Zentiva and Lilly. She has received a nominal grant from the South African Society of Psychiatrists (SASOP) for the drafting of these guidelines. Dr Liebenberg serves on the pharmaceutical advisory boards of Lilly, Janssen, Servier, Adcock and Pfizer. She has received honoraria, sponsorships and speakers' fees from Janssen, Cipla, Servier, Lundbeck, Aspen and Dr Reddy.

\section{Competing interests}

The authors declare that they have no financial or personal relationships which may have inappropriately influenced them in writing this article.

\section{Authors' contributions}

R.S. did the research and the drafting of the guidelines. R.L. provided valuable input pertaining to reviewing, advise, et cetera.

\section{References}

1. Cadell T, Davies $W$, Crichton A. An inquiry into the nature and origin of mental derangement: On attention and its diseases. J Atten Disord. 2008;12(3):200-204. https://doi.org/10.1177/1087054708315137

2. Hoffmann H. Lebenserinnerungen. In: Herzog CH, Siefert $\mathrm{H}$, editors. Gesammelte werke. Frankfurt, 1985

3. Hectman L. Attention-deficit disorders. In: Sadock BJ, Sadock VG, editors. Comprehensive textbook of psychiatry. 8th ed. Philadelphia, PN: Lippincott Comprehensive textbook of psychiatry.
William \& Wilkens, 2005; p. 3183-3204.

4. Goldstein S. Managing attention and learning disorders in late adolescence and adulthood. New York: Wiley; 1997.

5. Reimherr FW, Hedges DW, Strong RE, Wender PH. An open trial of venlafaxine in adult patients with attention deficit hyperactivity disorder. Presented at: The 35th Annual Meeting to the New Clinical Drug Evaluation Unit Program; 1995 May 1Jun 3; Orlando, FL.

6. National Resource Centre on AD/HD. Statistical prevalence of ADHD [homepage on the Internet]. c2013 [cited 2013 Mar 10]. Available from http://www. help4adhd.org/en/about/statistics

7. Wittchen $\mathrm{H}$, Jacobi F, Rehm J, et al. The size and burden of mental disorders and other disorders of the brain in Europe 2010. Eur Neuropsychopharmacol. 2011;21(9):655-679. https://doi.org/10.1016/j.euroneuro.2011.07.018

8. Faraone SV, Biederman J, Mick E. The age-dependent decline of attention deficit hyperactivity disorder: A meta-analysis of follow-up studies. Psychol Med. 2006;36(2):159-165. https://doi.org/10.1017/S003329170500471X
9. Fayyad J, De Graaf R, Kessler R, et al. Cross-national prevalence and correlates of adult attention-deficit hyperactivity disorder. Br J Psychiatry. 2007:190:402-409. https://doi.org/10.1192/bjp.bp.106.034389

10. Kessler RC, Adler L, Barkley R, et al. The prevalence and correlates of adult ADHD in the United States: Results from the national comorbidity survey replication. Am J Psychiatry. 2006;163(4):716-723. https://doi.org/10.1176/ajp.2006.163.4.716

11. Simon V, Czobor P, Balint A, et al. Prevalence and correlates of adult attentiondeficit hyperactivity disorder: Meta-analysis. Br J Psychiatry. 2009;194:204-211. https://doi.org/10.1192/bjp.bp.107.048827

12. Castle L, Aubert RE, Verbrugge RR, et al. Trends in medication treatment for ADHD. J Atten Disord. 2007;10(4):335-342. https://doi.org/10.1177/ 1087054707299597

13. Hodgkins P, Sasane R, Meijer WM. Pharmacologic treatment of attention-deficit/ hyperactivity disorder in children: Incidence, prevalence, and treatment pattern in the Netherlands. Clin Ther. 2011;33(2):188-203. https://doi.org/10.1016/j. clinthera.2011.03.001

14. Matte B, Anselmi L, Salum GA, et al. ADHD in DSM-5: A field trial in a large, representative sample of 18- to 19-year-old adults. Psychol Med. 2015;45(2):361-373. https://doi.org/10.1017/S0033291714001470

15. McLean A, Dowson J, Toone B, et al. Characteristic neurocognitive profile associated with adult attention-deficit/hyperactivity disorder. Psychol Med. 2014;34(4):681-692. https://doi.org/10.1017/S0033291703001296

16. Van de Voort JL, He JP, Jameson ND, Merikangas KR. Impact of the DSM-5 attention-deficit/hyperactivity disorder age-of-onset criterion in the US adolescent population. J Am Acad Child Adolesc Psychiatry. 2014;53(7):736-744. https://doi.org/10.1016/j.jaac.2014.03.005

17. Stein DJ, Williams DR, Kessler RC. The South African Stress and Health (SASH) study: A scientific base for mental health policy. S Afr Med J. 2009;99(5):337-344.

18. Abramovitch A, Goldzweig G, Schweiger A. Correlates of physical activity with intrusive thoughts, worry and impulsivity in adults with attention deficit/
hyperactivity disorder: A cross-sectional pilot study. Isr I Psychiatry Relat Sci. 2013;50:47-54.

19. Schoeman R. A funding model proposal for private health insurance for adult attention deficit/hyperactivity disorder in the South African context [Unpublished thesis in partial fulfilment for the degree Masters in Business Administration]. thesis in partial fulfilment for the
University of Stellenbosch; 2015.

20. Murray CJL, Vos T, Lozano R, et al. Disability-adjusted life years (DALYs) for 291 diseases and injuries in 21 regions, 1990-2010: A systematic analysis for the global burden of disease study 2010. Lancet. 2012;380(9859):2197-2223. https:// global burden of disease study 2010. Lance
doi.org/10.1016/S0140-6736(12)61689-4

21. Hinnenthal JA, Perwien AR, Sterling KL. A comparison of service use and costs among adults with ADHD and adults with other chronic diseases. Psychiatr Serv. 2005;56(12):1593-1599. https://doi.org/10.1176/appi.ps.56.12.1593

22. Polanczyk G, De Lima MS, Horta BL, et al. The worldwide prevalence of ADHD: A systematic review and meta-regression analysis. Am J Psychiatry. 2007;164(6): 942-946. https://doi.org/10.1176/ajp.2007.164.6.942

23. Secnik K, Swensen A, Lage MJ. Comorbidities and costs of adult patients diagnosed with attention-deficit hyperactivity disorder. PharmacoEconomics. 2005;23(1):93102. https://doi.org/10.2165/00019053-200523010-00008

24. Kupper $\mathrm{T}$, Haavik J, Drexler $\mathrm{H}$, et al. The negative impact of attention-deficit/ hyperactivity disorder on occupational health in adults and adolescents. Int Arch Occup Environ Health. 2012;85(8):837-847. https://doi.org/10.1007/s00420012-0794-0

25. Barkley R, Murphy KR, Fischer M. ADHD in adults: What the science says. New York: Guilford Press; 2007.

26. Bolea B, Adamou M, Arif M, et al. ADHD matures: Time for practitioners to do the same? J Psychopharmacol. 2012;6(6):766-770. https://doi.org/10.1177/ 0269881111410898

27. De Graaf R, Kessler RC, Fayyad J, et al. The prevalence and effects of adult attention-deficit/hyperactivity disorder (ADHD) on the performance of workers: Results from the WHO World Mental Health Survey Initiative. Occup Environ Med. 2008;65(12):835-842. https://doi.org/10.1136/oem.2007.038448

28. Birnbaum HG, Kessler RC, Lowe SW, et al. Costs of attention deficit-hyperactivity disorder (ADHD) in the US: Excess costs of persons with ADHD and their family members in 2000. Curr Med Res Opin. 2005;21(2):195-206. https://doi. org/10.1185/030079904X20303

29. Kleinman NL, Durkin M, Melkonian A, Mrkosyan K. Incremental employee health benefit costs, absence days, and turnover among employees with ADHD and among employees with children with ADHD. J Occup Environ Med. 2009;51(11):1247-1255. https://doi.org/10.1097/JOM.0b013e3181bca68c

30. Kessler RC, Lane M, Stang PE, Van Brunt DL. The prevalence and workplace costs of adult attention deficit hyperactivity disorder in a large manufacturing firm. Psychol Med. 2009;39(1):137-147. https://doi.org/ 10.1017/S0033291708003309

31. Kessler RC, Adler L, Ames M, et al. The prevalence and effects of adult attention deficit/hyperactivity disorder on work performance in a nationally representative sample of workers. J Occup Environ Med. 2005;47(6):565-572. https://doi. org/10.1097/01.jom.0000166863.33541.39

32. Asherson P, Akehurst R, Kooij JJ, et al. Under diagnosis of adult ADHD: Cultural influences and societal burden. J Atten Disord. 2012; 16(5 Suppl):20S-38S. https://doi.org/10.1177/1087054711435360

33. Barkley RA. Global issues related to the impact of untreated attention-deficit/ hyperactivity disorder from childhood to young adulthood. Postgrad Med. 2008;120(3):48-59. https://doi.org/10.3810/pgm.2008.09.1907 
34. Biederman J. Breaking news: The social and economic impact of ADHD. Paper presented at: The Attention Deficit Hyperactive Disorder (ADHD) AMA Briefing presented at: The Attention Deficit
Sep 9; Manhattan, New York; 2004.

35. Brook JS, Brook DW, Zhang C, et al. Adolescent ADHD and adult physical and mental health, work performance, and financial stress. Pediatrics. 2013; 131(1):5-13. https://doi.org/10.1542/peds.2012-1725

36. American Psychiatric Association (APA). Diagnostic and statistical manual of mental disorders, 5th edition [homepage on the Internet]. c2013 [cited $2013 \mathrm{Ma}$ 13]. Available from http://www.dsm5.org

37. National Institute for Health and Clinical Excellence (NICE). Attention deficit hyperactivity disorder. Diagnosis and management of ADHD in children, young people and adults [homepage on the Internet]. c2013 [cited 2013 Jun 24] Available from http://www.nice.org.uk/nicemedia/live/12061/42059/42059.pdf

38. Kessler RC, Adler L, Ames $M$, et al. The World Health Organization adult ADHD self-report scale (ASRS): A short screening scale for use in the general population. Psychol Med. 2005;35(2):245-256. https://doi.org/10.1017/ S0033291704002892

39. Barkley RA. Barkley Functional Impairment Scale (BFIS for adults). New York: Guilford Press; 2011.

40. Brown TE. Brown attention-deficit disorders scales, manual. San Antonio, TX: Psychological Corporation; 1996.

41. DuPaul GJ, Power TJ, Anastoloulus AD, Reid R. ADHD rating scale-IV: Checklists, norms and clinical interpretation. New York: Guilford Press; 1998.

42. Conners CK, Erhart D, Sparrow E. Conner's adult ADHD rating scales, technical manual. New York: Multi-Health Systems; 1999.

43. Ward MF, Wender PH, Reimherr FW. The Wender Utah rating scale: An aid in the retrospective diagnosis of childhood attention deficit hyperactivity disorder. Am Psychiatry. 1993;150(6):885-890.

44. Marchant BK, Reimherr FW, Wender PH, Gift TE. Psychometric properties of the self-Report Wender-Reimherr adult attention-deficit disorder scale. Ann Clin Psychiatry. 2015;27(4):267-277.

45. Epstein JN, Johnson DE, Conners CK. CAADID: The Conner's adult ADHD diagnostic interview for DSM-IV. North Tonawanda, NY: Multi-Health Systems Inc; 2001.

46. Kooij SJJ, Francken MH. Diagnostic interview for ADHD in adults (DIVA 2.0). Netherlands: DIVA foundation; 2010

47. Weiss MD, Dickson R, Wasdell M, et al. Weiss Functional Impairment Rating Scale Parent Report (WFIRS-P). Presented at: American Psychiatric Association 158th Annual Meeting; 2005 May 21-26; Atlanta, GA.

48. Breda V, Luiz Rovaris D, Vitola ES, et al. Does collateral retrospective information about childhood attention-deficit/hyperactivity disorder symptoms assist in the diagnosis of attention-deficit/hyperactivity disorder in adults? Findings from large clinical sample. Aust N Z J Psychiatry. 2015;50(6):557-565.

49. Dvorsky MR, Langberg JM, Molitor SJ, Bourchtein E. Clinical utility and predictive validity of parent and college student symptoms ratings in predicting an ADHD diagnosis. J Clin Psychol. 2016;72(4):401-418. https://doi.org/10.1002/ jclp.22268

50. Bolea-Alamanac B, Nutt DJ, Adamou M, et al. Evidence-based guidelines for the pharmacological management of attention deficit hyperactivity disorder: Update on recommendations from the British Association for Psychopharmacology. J Psychopharmacol. 2014;28(3):179-203. https://doi org/10.1177/0269881113519509

51. Boonstra AM, Oosterlaan J, Sergeant JA, Buitelaar JK. Executive functioning in adult ADHD: A meta-analytic review. Psychol Med. 2005;35(8):1097-1108. https://doi.org/10.1017/S003329170500499X

52. Asherson P. Clinical assessment and treatment of attention deficit hyperactivity disorder in adults. Expert Rev Neurother. 2005;5(4):525-539. https://doi. org/10.1586/14737175.5.4.525

53. Nutt DJ, Fone K, Asherson P, et al. Evidence-based guidelines for management of attention-deficit/hyperactivity disorder in adolescents in transition to adult services and in adults: Recommendations from the British Association for
Psychopharmacology. J Psychopharmacol. 2007;21(1):10-41. https://doi. org/10.1177/0269881106073219

54. Sonuga-Barke EJ, Sergeant JA, Nigg J, et al. Executive dysfunction and delay aversion in attention deficit hyperactivity disorder: Nosologic and diagnostic aversion in attention deficit hyperactivity disorder: Nosologic and diagnostic
implications. Child Adolesc Psychiatr Clin N Am. 2008;17:367-384. https://doi. implications. Child Adolesc Psychiz
org/10.1016/j.chc.2007.11.008

55. Knagenhjelm P, Ulberstad F. Qb test technical manual. Stockholm, Sweden: Qbtech au-Main: Insel; 2010.

56. Berger I, Goldzweig G. Objective measures of attention-deficit/hyperactivity disorder - A pilot study. Isr Med Assoc J. 2010;12:531-535.

57. Leark RA, Greenberg LM, Kindschi CL, et al. T.O.V.A. Professional manual test of variables of attention continuous performance test. Los Alamitos, CA: The TOVA Company; 2007.

58. Marshall PS, Hoelzle JB, HeyerdahI D, Nelson NW. The impact of failing to identify suspect effort in patients undergoing adult attention-deficit/hyperactivity disorder (ADHD) assessment. Psychol Assess. 2016;28(10):1289. https://doi. org/10.1037/pas0000247

59. World Health Organization. Mental health [homepage on the Internet]. 2014 [cited 2014 Aug 2]. Available from: http://www.who.int/features/factfiles/ mental_health/en/

60. Taylor D, Paton C, Kapur S. Attention deficit hyperactivity disorder. In: Taylor D, Paton C, Kapur S, editors. The Maudsley prescribing guidelines. Vol. 10 London: Informa Health, 2009; p. 263-265. https://doi.org/10.3109/
9780203092835
61. Drummond MF, Sculpher MJ, Torrance GW, et al. Methods for the economic evaluation of health care programmes. New York: Oxford University Press; 2005.

62. Jensen PS, Garcia JA, Glied S, et al. Cost-effectiveness of ADHD treatments: Findings from the multimodal treatment study of children with ADHD. Am Psychiatry. 2005;162(9):1628-1636. https://doi.org/10.1176/appi.ajp.162.9.1628

63. Wu EQ, Hodgkins P, Ben-Hamadi R, et al. Cost effectiveness of pharmacotherapies for attention-deficit hyperactivity disorder: A systematic literature review. CNS Drugs. 2012;26(7):581-600. https://doi.org/10.2165/11633900-00000000000000

64. Bradley C. The behavior of children receiving Benzedrine. Am J Psychiatry 1937;94:577-585. https://doi.org/10.1176/ajp.94.3.577

65. Conners C, Eisenberg L, Barcai A. Effect of dextroamphetamine on children: Studies on subjects with learning disabilities and school behavior problems. Arch Gen Psychiatry. 1967;17(4):478-485. https://doi.org/10.1001/archpsyc.1967. 01730280094011

66. Heal DJ, Smith SL, Findling RL. ADHD: Current and future therapeutics. Curr Top Behav Neurosci. 2012;9:361-390. https://doi.org/10.1007/7854_2011_125

67. Kooij SJJ, Bejerot S, Blackwell A, et al. European consensus statement on diagnosis and treatment of adult ADHD: The European Network Adult ADHD. BMC Psychiatry. 2010;10:67. https://doi.org/10.1186/1471-244X-10-67

68. Wilens $T E$, Spencer MD, Biederman MD. A review of the pharmacotherapy of adults with attention-deficit/hyperactivity disorder. J Atten Disord. 2002; 5(4):189-202. https://doi.org/10.1177/108705470100500401

69. Faraone SV, Spencer $T$, Aleardi $M$, et al. Meta-analysis of the efficacy of methylphenidate for treating adult attention-deficit/hyperactivity disorder. J Clin Psychopharmacol. 2004;24(1):24-29. https://doi.org/10.1097/01.jcp. 0000108984.11879 .95

70. Castells X, Ramos-Quiroga JA, Rigau D, et al. Efficacy of methylphenidate for adults with attention-deficit hyperactivity disorder: A meta-regression analysis. CNS Drugs. 2011;25(2):157-169. https://doi.org/10.1097/01.jcp.0000108984. 11879.95

71. Peterson K, McDonagh MS, Fu R. Comparative benefits and harms of competing medications for adults with attention-deficit hyperactivity disorder: A systematic review and indirect comparison meta-analysis. Psychopharmacology. 2008;197(1):1-11. https://doi.org/10.1007/s00213-007-0996-4

72. Canadian Attention Deficit Hyperactivity Disorder Resource Alliance (CADDRA). Canadian ADHD practice guidelines. Toronto: CADDRA; 2011

73. Spencer T, Wilens TE, Biederman J, Faraone SV, Ablon JS, Lapey K. A double blind, crossover comparison of methylphenidate and placebo in adults with childhood-onset attention-deficit hyperactivity disorder. Arch Gen Psychiatry. 1995;52:434-443. https://doi.org/10.1001/archpsyc.1995.03950180020004

74. Pennick M. Absorption of lisdexamfetamine dimesylate and its enzymatic conversion to d-amphetamine. Neuropsychiatr Dis Treat. 2010;6:317-327. https://doi.org/10.2147/NDT.S9749

75. Adler LA, Goodman DW, Kollins SH, et al. Double-blind, placebo-controlled study of the efficacy and safety of lisdexamfetamine dimesylate in adults with attention-
deficit/hyperactivity disorder. J Clin Psychiatry. 2008;69(9):1364-1373. https:// deficit/hyperactivity disorder. J
doi.org/10.4088/JCP.v69n0903

76. Findling RL, Childress AC, Cutler AJ, et al. Efficacy and safety of lisdexamfetamine dimesylate in adolescents with attention-deficit/hyperactivity disorder. J Am Acad dimesylate in adolescents with attention-deficit/hyperactivity disorder. J Am Acad
Child Adolesc Psychiatry. 2011;50(4):395-405. https://doi.org/10.1016/j. Child Adolesc
jaac.2011.01.007

77. Weisler R, Young J, Mattingly G, et al. Long-term safety and effectiveness of Lisdexamphetamine Dimesylate in adults with attention-deficit/hyperactivity Lisdexamphetamine Dimesylate in adults with attention-deficit/hyperactivity
disorder. CNS Spectrum. 2009;14:573-585. https://doi.org/10.1017/ disorder. CNS Sp
S1092852900024056

78. Jasinski DR, Krishnan S. Abuse liability and safety of oral lisdexamfetamine dimesylate in individuals with a history of stimulant abuse. J Psychopharmacol. 2009;23(4):419-427. https://doi.org/10.1177/0269881109103113

79. Faraone SV, Buitelaar J. Comparing the efficacy of stimulants for ADHD in children and adolescents using meta-analysis. Eur Child Adolesc Psychiatry. 2010;19(4):353-364. https://doi.org/10.1007/s00787-009-0054-3

80. Bushe CJ, Savill N. Atomoxetine in children and adolescents with attention-deficit/ hyperactivity disorder. Systematic review of review papers 2009-2011. An update for clinicians. J Cent Nerv Syst Dis. 2011;3:3209-3217. https://doi.org/10.4137/ jensd.s4391

81. Michelson D, Adler L, Spencer T, et al. Atomoxetine in adults with ADHD: Two randomized, placebo-controlled studies. Biol Psychiatry. 2003;53:112-120. https://doi.org/10.1016/S0006-3223(02)01671-2

82. Connor DF, Fletcher KE, Swanson JM. A meta-analysis of clonidine for symptoms of attention-deficit hyperactivity disorder. I Am Acad Child Adolesc Psychiatry. 1999;40(3):307-314. https://doi.org/10.1097/00004583 199912000-00017

83. Scahill L, Chappell PB, Kim YS, et al. A placebo-controlled study of guanfacine in the treatment of children with tic disorders and attention deficit hyperactivity disorder. Am J Psychiatry. 2001;158:1067-1074. https://doi.org/10.1176/appi. ajp.158.7.1067

84. Biederman J, Melmed RD, Patel A, et al. A randomized, double-blind, placebocontrolled study of Guanfacine extended release in children and adolescents with attention-deficit/hyperactivity disorder. Pediatrics. 2008;121:73-84. https://doi. org/10.1542/peds.2006-3695

85. Taylor FB, Russo J. Comparing guanfacine and dextroamphetamine for the treatment of adult attention-deficit/hyperactivity disorder. J Clin Psychopharmacol. 2001;21(2):23-228. https://doi.org/10.1097/00004714200104000-00015 
86. Wilens TE, Morrison NR, Prince J. An update on the pharmacotherapy of attentiondeficity/hyperactivity disorder in adults. Expert Rev Neurother. 2011;11(10):14431465. https://doi.org/10.1586/ern.11.137

87. Kahbazi M, Ghoreishi A, Rashiminejad F, Mohammadi MR, Kamalipour A, Akhondzadeh S. A randomized, double-blind and placebo-controlled trial of Modafanil in children and adolescents with attention deficit and hyperactivity disorder. Psychiatr Res. 2009;16:234-237. https://doi.org/10.1016/j. disorder. Psychiatr
psychres.2008.06.024

88. Arnold VK, Feifel D, Earl CG, Yang R, Adler LA. A 9-week, randomized, double-blind, placebo-controlled, parallel-group, dose-finding study to evaluate the efficacy and safety of modafinil as treatment for adults with ADHD. J Atten Disord. 2012;18(2):133-144.

89. Cephalon. Cephalon reports no benefit from Provigil in study of adults with ADHD. West Chester, PA: Cephalon; 2000.

90. Adler LA, Resnick S, Kunz M, Devinsky O. Open label trial of venlafaxine in adult with attention deficit disorder. Psychopharmacol Bull. 1995;31:7985-788.

91. Findling RL, Schwartz MA, Flannery DJ, Manos MJ. Venlafaxine in adults with attention-defcit/hyperactivity disorder. J Clin Psychiatr. 1996;57(5):1147-1153.

92. Conners K, Casat C, Gualtieri T, et al. Bupropion hydrochloride in attention deficit disorder with hyperactivity. J Am Acad Child Adolesc Psychiatry. 1996;35(10):1314disorder with hyperactivity. J Am Acad Child Adolesc Psychiatry.

93. Wilens T, Prince J, Biederman J, et al. An open study of sustained-release bupropion in adults with ADHD and substance use disorders. Presented at: The 48th Annual Meeting of the American Academy of Child and Adolescent Psychiatry (AACAP); 2001 Oct 23-28; Honolulu, HI.

94. Wilens $T$, Haight BR, Horrigan JP, et al. Bupropion XL in adults with ADHD: A randomized, placebo-controlled study. Biol Psychiatry. 2005;57(7):793-801. https://doi.org/10.1016/j.biopsych.2005.01.027

95. Reimherr FW, Hedges DW, Strong RE, Marchant BK, Williams ED. Bupropion SR in adults with ADHD: A short-term, placebo-controlled trial. Neuropsychiatr Dis Treat. 2005;1(3):245-251.

96. Maneeton N, Maneeton B, Srisurapanont M, Martin SD. Bupropion for adults with attention-deficit hyperactivity disorder: Meta-analysis of randomized, placebocontrolled trials. Psychiatry Clin Neurosci. 2011;65(7):611-617. https://doi. org/10.1111/j.1440-1819.2011.02264.x

97. Wender PH, Wood DR, Reimherr FW, Ward M. An open trial of pargyline in the treatment of attention deficit disorder, residual type. Psychiatry Res. 1983;9:329226. https://doi.org/10.1016/0165-1781(83)90006-9

98. Wender PH, Wood DR, Reimherr FW. Pharmacological treatment of attention deficit disorder residual type in adults. Psychopharmacol Bull. 1985;21:222-230.

99. Ernst M. MAOI treatment of adult ADHD. Paper presented at: The NIMH Conference on Alternative Pharmacology of ADHD; Washington, DC: National Institute of Mental Health (NIMH); 1996.

100. Ernst $M$, Liebenauer $L$, Jons $P$, et al. Selegiline in adults with attention deficit hyperactivity disorder: Clinical efficacy and safety. Psychopharmacol Bull. 1996;32:327-344.

101. MTA Cooperative Group. A 14-month randomized clinical trial of treatment strategies for attention-deficit/hyperactivity disorder. Multimodal treatment study of children with ADHD. Arch Gen Psychiatry. 1999;56:1073-1086. https:// doi.org/10.1001/archpsyc.56.12.1073

102. Saffren $S A$, Otto $M W$, Sprich $S$, Winett $C L$, Wilens $T E$, Biederman J, et al. Cognitive-behavioural therapy for ADHD in medication-treated adults with continued symptoms. Behav Res Ther. 2005;43:831-842. https://doi. org/10.1016/j.brat.2004.07.001

103. Young $S$, Khondoker M, Emilsson B, et al. Cognitive-behavioural therapy in medication-treated adults with attention-deficit/hyperactivity disorder and comorbid psychopathology: A randomized controlled trial using multi-leve analysis. Psychol Med. 2015;45(13):2793-2804. https://doi.org/10.1017/ S0033291715000756

104. Philipsen A, Jans T, Graf E, et al. Effects of group psychotherapy, individual counselling, methylphenidate, and placebo in the treatment of adult attentiondeficit/hyperactivity disorder: A randomized clinical trial. JAMA Psychiatry. 2015;72(12):1199-1210. https://doi.org/10.1001/jamapsychiatry.2015.2146

105. Bueno VF, Kozasa EH, da Silva MA, Alves TM, Louzã MR, Pompéia $S$, et al. Mindfulness meditation improves mood, quality of life, and attention in adults with attention deficit hyperactivity disorder. Biomed Res Int. 2015;2015:962857. https://doi.org/10.1155/2015/962857
106. Hesslinger B, Tebartz van Elst L, Nyberg E, et al. Psychotherapy of attention deficit hyperactivity disorder in adults: A pilot study using a structured skills training programme. Eur Arch Psychiatry Clin Neurosci. 2002:252:177-184. training programme. Eur Arch Psychiatry Cin
https://doi.org/10.1007/s00406-002-0379-0

107. Wiggens D, Singh K, Getz HG, Hutchins DE. Effects of brief group intervention for adults with attention deficit/hyperactivity disorder. J Ment Health Couns. 1999;21:82-92.

108. Stevenson CS, Whitmont S, Bornholt L, Livesey D, Stevenson RJ. A cognitive remediation programme for adults with attention deficit hyperactivity disorder. Aust N Z J Psychiatry. 2002;36:610-616. https://doi. org/10.1046/j.1440-1614.2002.01052.x

109. Ratey JJ, Greenberg MS, Bemporad JR, Lindem KJ. Unrecognized attentiondeficit hyperactivity disorder in adults presenting for outpatient psychotherapy. J Child Adolesc Psychopharmacol. 1992;2:267-275. https://doi.org/10.1089/ cap.1992.2.267

110. Arns $M$, Heinrich $H$, Strehl U. Evaluation of neurofeedback in ADHD: The long and winding road. Biol Psychol. 2014;95:108-115. https://doi.org/10.1016/j. biopsycho.2013.11.013

111. Arns M, de Ridder S, Strehl U, Breteler M, Coenen A. Efficacy of neurofeedback treatment in ADHD: The effects on inattention, impulsivity and hyperactivity: A meta-analysis. Clin EEG Neurosci. 2009;40:180-189. https://doi. org/10.1177/155005940904000311

112. Mayer K, Blume F, Wyckoff SN, Brokmeier LL, Strehl U. Neurofeedback of slow cortical potentials as a treatment for adults with Attention Deficit-/Hyperactivity Disorder. Clin Neurophysiol. 2016;127(2):1374-1386. https://doi.org/10.1016/j. clinph.2015.11.013

113. Sonuga-Barke EJS, Brandeis D, Cortese S, et al. Non-pharmacological interventions for ADHD: Systematic review and meta-analyses of randomized controlled trials of dietary and psychological treatments. Am J Psychiatry. 2013;170(3):275-289. https://doi.org/10.1176/appi.ajp.2012.12070991

114. Lambourne K, Tomporowski P. The effect of exercise-induced arousal on cognitive task performance: A meta-regression analysis. Brain Res. 2010;1341:12-24. https://doi.org/10.1016/j.brainres.2010.03.091

115. Randolph J. Lifestyle factors and ADHD: The positive role of physical activity. Nat| Acad Neuropsychol Bull. 2015;30(1):14-15.

116. Gapin JI, Etnier JL. The relationship between physical activity and executive function performance in children with attention deficit hyperactivity disorder. Sport Exerc Psychol. 2010;32:753-763. https://doi.org/10.1123/jsep.32.6.753

117. Chang Y-K, Liu S, Yu H-H, Lee Y-H. Effect of acute exercise on executive function in children with Attention Deficit Hyperactivity Disorder. Arch Clin Neuropsychol. 2012;27:225-237. https://doi.org/10.1093/arclin/acr094

118. Piepmeier AT, Shih $\mathrm{C}-\mathrm{H}$, Whedon $\mathrm{M}$, et al. The effect of acute exercise on cognitive performance in children with and without ADHD. J Sport Health Sci. 2015;4:97-104. https://doi.org/10.1016/j.jshs.2014.11.004

119. Pontifex MB, Saliba BJ, Raine LB, Picchietti DL, Hillman CH. Exercise improves behavioural, neurocognitive, and scholastic performance in children with Attention-Deficit/Hyperactivity Disorder. J Paediatr. 2013;62:543-551. https:// doi.org/10.1016/j.jpeds.2012.08.036

120. Medina JA, Netto LB, Muszkat $M$, et al. Exercise impact on sustained attention of ADHD children, methylphenidate effects. Atten Defic Hyperact Disord. 2010;2:49-58. https://doi.org/10.1007/s12402-009-0018-y

121. Halperine JM, Healey DM. The influences of environmental enrichment, cognitive enhancement, and physical exercise on brain development: Can we alter the developmental trajectory of ADHD? Neurosci Biobehav Rev. 2011;35(3):621-634. https://doi.org/10.1016/j.neubiorev.2010.07.006

122. Jones GJ. Acute exercise and executive function in young adults with ADHD. Dissertation in fulfilment for the degree Doctor of Philosophy. University of lowa; 2015 [cited 2015 July 7]. Available from http://ir.uiowa.edu/etd/1651

123. Neudecker C, Mewes N, Reimers AK, Woll A. Exercise interventions in children and adolescents with ADHD: A systematic review. J Atten Disord. 2015:1-18. https://doi.org/10.1177/1087054715584053

124. Cooper RE, Tye C, Kuntsi J, Vassos E, Asherson P. Omega-3 poly-unsaturated fatty acid supplementation and cognition: A systematic review and metaanalysis. J Psychopharmacol. 2015;29(7):753-763. https://doi.org/10.1177/ 0269881115587958

125. Bazire S. Pscyhotropic drug directory 2012. The professionals pocket handbook and Aide Memoire. Cheltenham: Lloyd-Reinhold Communications; 2012. 